\title{
Perceived barriers and facilitators of using dietary modification for CKD prevention among African Americans of low socioeconomic status: a qualitative study
}

\author{
Amber E Johnson', L Ebony Boulware 1,2,3,4, Cheryl AM Anderson³, ${ }^{3,5}$ Tatpong Chit-ua-aree ${ }^{6}$, Kimberly Kahan $^{6}$, \\ LaPricia Lewis Boyér', Yang Liu ${ }^{6}$ and Deidra C Crews ${ }^{2,6,7^{*}}$
}

\begin{abstract}
Background: Factors influencing the use of dietary interventions for modification of CKD risk among African Americans have not been well-explored. We assessed perceived barriers and facilitators of CKD prevention through dietary modifications among African Americans with low socioeconomic status (SES) and at high risk for CKD.

Methods: We conducted a qualitative study involving three 90 minute focus groups of low SES (limited education, unemployed, uninsured, or income $<\$ 25,000 /$ year) African American residents of Baltimore, Maryland $(N=17)$, who were aged 18-60 years, with no known history of CKD and (1) a family history of end stage renal disease and (2) self-reported diabetes, hypertension, cardiovascular disease, HIV or obesity. A trained moderator asked a series of 21 closed and open-ended questions. Group sessions were recorded, transcribed, and two independent investigators reviewed transcripts to identify common themes.
\end{abstract}

Results: Participants' mean (SD) age was 39.8 (12.4) years. Most (59\%) were female and earned $<\$ 5,000 /$ year (71\%). One quarter (24\%) had self-reported diabetes and over half had hypertension (53\%). Few (12\%) perceived their CKD risk as high. Perceived barriers to CKD prevention through dietary change included the expense and unavailability of healthy foods, family member preferences, convenience of unhealthy foods, and inability to break lifelong habits. They identified vouchers for healthy foods, family-based interventions, nutritional counseling and group gatherings for persons interested in making dietary changes as acceptable facilitators of dietary CKD prevention efforts.

Conclusions: Low SES African Americans at high risk for CKD had limited perception of their risk but they identified multiple barriers and potential facilitators of CKD prevention via dietary modifications which can inform future studies and public health interventions.

Keywords: Renal, Diet, Disparities, Race, Chronic kidney disease

\section{Background}

African Americans are more than twice as likely to live in poverty as are whites [1] and socioeconomic factors are believed to contribute in complex ways to racial disparities in chronic kidney disease (CKD) [2]. Dietary factors may play a role in these disparities. Specific dietary

\footnotetext{
* Correspondence: dcrews1@jhmi.edu

${ }^{2}$ Welch Center for Prevention, Epidemiology and Clinical Research, Johns

Hopkins Medical Institutions, Baltimore, Maryland, USA

${ }^{6}$ Division of Nephrology, Department of Medicine, Johns Hopkins University School of Medicine, Baltimore, Maryland, USA

Full list of author information is available at the end of the article
}

patterns or components have been associated with greater risk of prevalent $[3,4]$ or incident CKD $[5,6]$. Several dietary patterns have been associated with CKD progression in observational studies [7-10], including diets which are non-adherent to the Dietary Approaches to Stop Hypertension (DASH) trial diet [11]. Additionally, diets high in fruits and vegetables and low in dietary acid load (similar to the DASH diet [12]) have demonstrated kidney-related benefits in controlled studies $[13,14]$. African Americans are more likely to experience food insecurity [15] and/or live in "food deserts" [16], which 
may contribute to documented racial disparities in diet quality [17]. For example, African Americans with hypertension are less likely to follow a DASH trial accordant diet than are whites [18], despite their being shown to potentially receive the greatest blood pressure benefit from the DASH diet [19].

Although reasons for poorer diet quality among African Americans compared to whites are not fully understood, they are likely multifactorial, including African Americans' perceptions of healthful dietary practices, access to healthful foods, cultural and familial norms, and preferences [16,20-22]. Prior studies have demonstrated African Americans' perceived risk of CKD is low, presenting one potential barrier to CKD prevention [23-25]. However, little is known about African Americans' views on ways to prevent CKD through dietary interventions. Identification of factors likely to influence the success of dietary interventions among African Americans at high risk for CKD could greatly enhance preventive strategies.

We performed a qualitative study to elicit perspectives on CKD prevention via dietary modifications among African Americans of low socioeconomic status (SES), given empirical data suggesting their particularly high risk of adverse kidney outcomes [26-28]. We focused our study on African Americans with a family history of ESRD as this risk factor is more common among African Americans than whites, and is associated with a 2-fold greater risk of developing ESRD [29]. To inform future effectiveness studies aimed at preventing CKD among high-risk African Americans, we examined participants' views on specific components of the DASH diet which has been associated with lower risk of kidney function decline [11] and other favorable health outcomes [30-33].

\section{Methods}

\section{Study overview}

We performed three focus groups of a total of 17 selfidentified African Americans with low socioeconomic status and high risk for CKD to assess their CKD knowledge as well as their perceived barriers and facilitators of CKD prevention through changes in dietary practices. Our approach was guided by the Consolidated Criteria for Reporting Qualitative Research (COREQ) checklist [34].

\section{Participant selection and setting}

African Americans were eligible to participate if they were English-speaking, aged 18-60 years and (1) had a self-reported family history of end-stage renal disease (ESRD, affecting a parent or sibling), (2) had a selfreported biological risk factor for CKD (self-reported history of diabetes, hypertension, cardiovascular disease, HIV or obesity), and (3) were of low self-reported SES (defined as one or more of either less than a high school education, unemployment, lack of health insurance, or annual personal income less than $\$ 25,000)$. We excluded those with a self-report of a CKD diagnosis at the time of enrollment or a history of kidney transplant. We recruited participants through patients treated in dialysis units in the Baltimore, MD metropolitan area. We provided information about our study to dialysis patients, and we asked them to pass this along to their potentially eligible relative(s) who then contacted us directly with interest in participating in the study. All participants provided written consent, and the Institutional Review Board of the Johns Hopkins University approved the study protocol.

\section{Data collection}

We conducted three separate focus groups between June and October 2012. Each participant completed a questionnaire at the beginning of their group session (which was read to them, if needed) assessing sociodemographic information, including age, gender, education, marital status, insurance status, employment status, annual income, and healthcare utilization. The questionnaire also assessed participants' personal perceptions of their CKD risk by asking "What do you think are your chances of getting kidney failure in the future-low, medium or high?" At the beginning of each focus group, and following the completion of the questionnaire, participants were given and read a one-page flyer titled 'What is Kidney Disease?' that provided educational information about the kidney ("The kidneys are small, bean-shaped organs on either side of your spine. The kidneys' main job is to take out waste and extra fluid from your body. They make urine from this waste".) [35]; and were provided general details about the treatment of kidney disease in order to provide a framework for the focus group. Additionally, participants were told, "Currently, African Americans develop kidney failure up to 4 times more often than whites, and the two main causes of kidney failure are diabetes (sugar) and high blood pressure".

All focus group sessions were 90 minutes in length and were facilitated by the same trained moderator, who utilized a standardized guide developed by the study team to conduct the sessions (Table 1 and Additional file 1). We asked participants a series of closed and open-ended questions about their perceptions regarding CKD and its prevention through dietary modifications grouped into three sections (1) knowledge/beliefs, (2) needs and (3) acceptable interventions. At the end of the 'knowledge/beliefs' section, we asked "Have you ever heard of the DASH diet (Dietary Approaches to Stop Hypertension diet)? If so, what do you know about it?" We then described the DASH diet as "The DASH diet is rich in fruits, vegetables and low fat dairy foods, and low in salt and saturated fat; and it is a good diet to follow for lowering your chances of getting kidney disease". 


\section{Table 1 Sample questions (10 of a total of 21 ) from the focus group moderator's discussion guide}

A. Do you think that what you eat can affect your chances of getting kidney disease? If so, how?

B. What do you think are good foods to eat to lower your chances of getting kidney disease?

C. What do you think are foods to avoid so that you can lower your chances of getting kidney disease?

D. Are there things that your family member with kidney failure did or didn't eat that you think raised their chances of getting kidney disease?

E. Are there things related to food that you currently do that you think raises your chances of getting kidney disease?
F. The (Dietary Approaches to Stop Hypertension) DASH diet is rich in fruits, vegetables and low fat dairy foods, and low in salt and saturated fat; and it is a good diet to follow for lowering your chances of getting kidney disease. What do you think you would need in order to be able to follow the DASH diet? (e.g. education, money, transportation to better grocery store, etc)

G. Do you think you would you be able to find these types of foods in your local food store?

$H$. Do you have everything that you would need in order to prepare your food at home? (e.g. oven, refrigerator, microwave, freezer, electricity/gas)

I. If someone wanted to teach you how to follow the DASH diet, who should that person be?

J. Should the person who teaches you about the DASH diet be someone who has followed it before, or does it matter?

\section{Analysis}

The focus group discussions were audio recorded and transcribed verbatim. The grounded theory approach was used for content analysis, given limited available data about the knowledge and beliefs about dietary practices among African Americans at high risk for CKD. Grounded theory is a qualitative tool to derive theories when the literature is lacking on a subject. It uses data sampling through tools such as focus groups to gain understanding of a subject [36,37]. Two investigators independently reviewed the transcripts after they had been professionally transcribed by an outside company. The coding scheme derived represented concepts addressed by participants during the discussions. These concepts were further refined and categorized to develop a list of key themes regarding perceptions of CKD and potential barriers and facilitators of CKD prevention via dietary changes in this population. The coding process was as follows. Two investigators (T.C. and A.J.) generated their own lists of codes for each individual focus group session. After which, there were constant comparisons within codes and between coders until no new ideas emerged. ATLAS.ti version 6.2.27 (Berlin, Germany) was used for data management and allowed the investigators to create memos and visually depict the emerging themes. A third investigator (D.C.) adjudicated differences in interpretation of emergent themes. Inter-rater reliability occurred with constant comparisons between all coders. Representative excerpts from the participant quotes which corresponded to the emergent themes were selected by the same three investigators for inclusion in the manuscript. Identifiable participant data were stored in a locked file cabinet in the office of the lead investigator and only deidentified data were analyzed by the study team.

\section{Results}

Participant characteristics

A total of 75 individuals contacted our research team with interest in participating in the study. After initial screening, 20 of 75 met full eligibility criteria, and we invited them to attend a focus group session with a target of 6-8 participants per group. Seventeen individuals ultimately attended one of the three focus groups (consisting of 6, 4, and 7 participants each). No further groups were scheduled due to the emergence of no new major themes in the third session. A majority of participants were female, high school graduates, unmarried, unemployed, and/or earned less than or equal to $\$ 10,000$ per year. (Table 2) Participants self-reported several medical conditions, including being $\geq 30$ pounds overweight (reported by 100\%), diabetes, hypertension, heart disease, and HIV. All but one participant had been seen by a clinician in the previous one year. Most (88\%) participants perceived their risk of CKD to be 'low' or 'medium'.

\section{Knowledge about CKD causes and risk factors}

Participants expressed several ideas about potential causes of CKD and CKD risk factors, encompassed by four main themes (Table 3):

\section{CKD can be caused by medications or inadequate water intake}

Participants believed that kidney problems could be caused by or exacerbated by medication use, and some believed dietary supplements might help to prevent kidney disease. Participants also believed that inadequate water intake could lead to CKD, as could the frequent consumption of certain other beverages (e.g. soft drinks and alcoholic beverages).

One participant described some thoughts about medications and kidney injury:

"In his case [referring to a relative with kidney disease], it was more the fact that the medication that he was taking was overpowering his kidneys. So by overpowering his kidneys, his kidneys couldn't flush them out. And the more he was taking the medicine, 
Table 2 Focus group participant characteristics

\begin{tabular}{|c|c|}
\hline Characteristic & $n=17(\%)$ \\
\hline Age in years, mean (SD) & $39.8(12.4)$ \\
\hline Female gender & $10(59)$ \\
\hline \multicolumn{2}{|l|}{ Highest level of education } \\
\hline High school & $10(59)$ \\
\hline 2 year college & $2(12)$ \\
\hline College or graduate/professional school & $5(30)$ \\
\hline \multicolumn{2}{|l|}{ Marital status } \\
\hline Married & $4(24)$ \\
\hline Living with a partner & $2(12)$ \\
\hline Separated & $2(12)$ \\
\hline Never married & $9(53)$ \\
\hline \multicolumn{2}{|l|}{ Health insurance } \\
\hline Private & $2(12)$ \\
\hline Medicare or Medicaid & $8(47)$ \\
\hline None & $5(29)$ \\
\hline Other & $2(12)$ \\
\hline \multicolumn{2}{|l|}{ Employment } \\
\hline Unemployed & $11(65)$ \\
\hline Part time & $3(18)$ \\
\hline Full time & $3(18)$ \\
\hline Yearly income $\leq \$ 10,000$ & $14(83)$ \\
\hline \multicolumn{2}{|l|}{ Chronic conditions } \\
\hline Obesity ( $\geq 30$ lbs overweight) & $17(100)$ \\
\hline Diabetes & $4(24)$ \\
\hline Hypertension & $9(53)$ \\
\hline Heart disease & $2(12)$ \\
\hline HIV & $1(6)$ \\
\hline \multicolumn{2}{|l|}{ Family member with CKD* } \\
\hline Father & $6(35)$ \\
\hline Mother & $3(18)$ \\
\hline Sibling(s) & $10(59)$ \\
\hline Other & $1(6)$ \\
\hline \multicolumn{2}{|l|}{ Time since last seen by a clinician } \\
\hline Less than 3 months & $11(65)$ \\
\hline Less than a year & $5(29)$ \\
\hline More than a year & $1(6)$ \\
\hline
\end{tabular}

*Not mutually exclusive.

the more he couldn't flush them out in time enough. So it broke them down".

\section{CKD can be caused by frequent consumption of certain foods}

Participants commonly reported their beliefs about the in a relation between consumption of 'unhealthy' foods and increased risk of CKD. Participants also reported beliefs that avoidance of fast, fried, canned or processed foods could potentially lower an individual's risk of CKD. They also believed that food preparation (including under- or overcooking food, and the use of seasonings) could play a role in determining CKD risk. A participant commented:

"I do think I'm at high risk 'cause I don't really watch what I eat. I eat a lot of fried foods like she stated, starches, things like that. I really am at high risk. I've tried to slow down".

Another participant commented:

"I think most people lack more vegetables than anything. Even though sometimes a lot of people think some vegetables may be good for you, but it's what we put on the vegetables as well that doesn't help our diets as well..."

\section{CKD is often caused by other chronic diseases}

While some participants were unaware that kidney disease can be caused by other conditions, many associated kidney disease with chronic diseases such as hypertension and diabetes. They also identified that dietary habits may relate to risk of CKD through its influence on risk of these other chronic conditions. For instance, one participant commented:

"Because my father got it through diabetes, and it's the food that he ate which caused him to obtain diabetes, and then he just went downhill from there. And I had actually had gestational with my daughter, and I had to change my whole diet around. So I believe that that's a big reason why".

\section{Family history and ethnicity are risk factors for CKD}

Participants believed family history plays a role in an individual's risk of CKD, and they shared many insights into their family members' experiences with CKD.

"I got a niece who just had a kidney transplant, and I got an older brother, he's on dialysis, right, so I got some fears that I might get it one day, you know what I mean? I'm not saying a real high risk, but a medium risk, you know, see what I'm saying? Because I've got two family members suffering with, you know, my mother never had it, but, you know, I think it runs in my family".

Participants also shared their perceptions of racial differences in kidney disease burden. One participant commented: 
Table 3 Emergent themes

\begin{tabular}{lll}
\hline $\begin{array}{l}\text { Knowledge about CKD causes } \\
\text { and risk factors }\end{array}$ & $\begin{array}{l}\text { Perceived barriers to CKD prevention } \\
\text { through dietary changes }\end{array}$ & $\begin{array}{c}\text { Acceptable interventions and facilitators of } \\
\text { CKD prevention through dietary changes }\end{array}$ \\
\hline $\begin{array}{l}1 \text { CKD can be caused by medications } \\
\text { or inadequate water intake }\end{array}$ & $\begin{array}{c}1 \text { Healthy foods are expensive and } \\
\text { unavailable in certain neighborhoods }\end{array}$ & 1 Education and nutritional counseling \\
$\begin{array}{l}2 \text { CKD can be caused by frequent } \\
\text { consumption of certain foods }\end{array}$ & $\begin{array}{r}2 \text { Unhealthy foods are more convenient } \\
\text { to prepare or access }\end{array}$ & 2 Raising CKD awareness \\
$\begin{array}{l}3 \text { CKD is often caused by other chronic } \\
\text { diseases }\end{array}$ & $\begin{array}{l}3 \text { Unhealthy dietary practices have been a } \\
\text { lifelong habit }\end{array}$ & $\begin{array}{l}\text { 3 Home-based and family Interventions to } \\
\text { increase DASH diet adherence }\end{array}$ \\
$\begin{array}{l}4 \text { Family history and ethnicity are risk } \\
\text { factors for CKD }\end{array}$ & $\begin{array}{l}\text { Family members' dietary requirements and } \\
\text { preferences challenge ability to change habits }\end{array}$ & 4 Community-based interventions \\
\hline
\end{tabular}

"I still have that problem of, why is there so many African Americans? And I do know that there are a lot of Caucasians that end up suffering from dialysis, but it seems like they don't suffer until they get like their eighties, like between 75, they're 80, where so our community is so young".

\section{Perceived barriers to CKD prevention through dietary changes}

No participants reported prior knowledge of the DASH diet when asked by our moderator. Following a description of the DASH diet, focus group participants described factors that might hinder their ability to follow such a dietary pattern and potentially lower their risk of CKD. These factors were encompassed by four main themes (Table 3):

\section{Healthy foods are expensive and unavailable in certain neighborhoods}

Several group members reported that financial limitations pose a barrier to following a healthful diet and that fresh produce is often not plentiful in low-income neighborhoods.

One participant stated:

"This is somewhat off the beaten path, but if your socioeconomic conditions don't dictate that you have the money, then that puts you at a disadvantage to someone that has the wherewithal to buy these fruits and vegetables, so therefore, you're in a catch-22 to a certain extent or maybe you have to push something else aside to do that. Change your budget around a little bit, you know?”

Another participant commented:

"And what we have in our neighborhoods, and most low-income neighborhoods, is fast-food restaurants everywhere. You hardly see a farmers' market or fresh produce stand, or even fresh produce in the supermarket. And as soon as you walk in the market the first thing you see is cakes, cookies, chips, cereal with loads of sugar".
Unhealthy foods are more convenient to prepare or access Several participants reported convenience of food preparation as influencing dietary choices and a potential barrier to healthy eating. One participant commented:

"Yes, the fried foods, the starches are a lot easier to cook. It's not easier to cook, it's quicker. It's a quick meal, 30 minutes and I'm done. But I need to learn how to incorporate some green vegetables and salads in there as well".

\section{Unhealthy dietary practices have been a lifelong habit} Participants commonly reported that unhealthy dietary habits began during childhood and extended into their adulthoods. They shared their perceptions regarding the difficulty of changing long-standing lifestyle patterns. One participant remarked:

"It's generational, how we was brought up".

\section{Family members' dietary requirements and preferences challenge ability to change habits}

While some participants reported that they lived alone, most reported living with family members and/or friends. Those who lived with others expressed their dietary practices were affected by the dietary requirements and preferences of household members. One participant commented:

"Yeah, because my family-all of them eat fried foods and, you know, unhealthy foods. Order out pizza and all of that".

\section{Acceptable interventions and facilitators of CKD} prevention through dietary changes

Participants shared their thoughts on interventions that would be acceptable for enhancing their ability to follow a DASH-like diet and shared ideas for raising awareness about CKD prevention, encompassed by 5 main areas (Table 3): 


\section{Education and nutritional counseling}

Participants reported they believed the ideal person(s) to educate people about recommended dietary changes included doctors, nutritionists/dieticians and social workers -though some felt the term "social worker" held a negative societal connotation. While participants reported they did not feel it mattered whether educators were members of their community, some felt that in order to teach a certain dietary pattern, the educator would have to follow it as well.

"Because if you're going try to teach me something, you can't tell me nothing that you don't know. So you have to lead by example, so I'm going to have to know that you tasted it, tried it, and seen for yourself that it works".

Participants felt that once educated, the onus of behavior change was on the individual. For example, some had met with nutritionists in the past but related they struggled to adhere to the recommended diet thereafter. One participant explained,

"I have met with [a nutritionist], but I go off. I just go off. I'd be good for two or three weeks, and then I want to give myself a treat, and once I do that, I'm off again".

\section{Raising CKD Awareness}

Participants conveyed their support for efforts to raise community awareness of CKD. A participant stated,

"I think there should be more informative sessions about the kidney, chronic kidney disease because also people, especially black Americans, are not aware of the food that they eat that affects these things. So that's probably one way of trying to reduce it".

\section{Home-based and Family Interventions to Increase DASH Diet Adherence}

Participants identified that support in the home would facilitate healthy lifestyle changes, including assistance with meal preparation. When asked by our moderator, "Do you have everything that you would need in order to prepare your food at home?", all participants acknowledged that they had adequate appliances in the home to support meal preparation. While some felt it would be a challenge to engage family members in following the DASH diet, others described ways in which following the DASH diet would be feasible for their families:

"I think one of the things that may help you with the $D A S H$ diet is if you sit down with other family members and you discuss the situation about it trying to be from a preventive standpoint, say we're all going to go on it a support-type thing, and say let's try it this way".

There was also some discussion about whether, as part of an intervention, participants would allow others into their homes to assess whether they had DASH-diet adherent foods. Most participants felt this would be acceptable. One person remarked:

"I say yes because the whole purpose of them coming there is because you've accepted the fact that you need to change your eating habits. So they're bringing to the forefront what is considered to be bad food that's damaging to your system or what's damaging to hurt you. So you invite them into the presence of your home, you invite them into your kitchen, this is where the problem lies. Why not? Why not open your cabinets? Remove the sheets. Remove the veil. Let it out".

\section{Community-based interventions}

Participants offered several ideas for acceptable community-based interventions including DASH diet gatherings in the community, teaching children about healthful eating at schools, church based activities and support groups. One participant described how a group intervention held in the home would help to establish a supportive network:

"Or you could even have like a DASH diet party. You know, have a Tupperware party? Just have a DASH diet party... That way you can do it in a group setting at your home so you won't feel uncomfortable".

Participants expressed concern for the future of children growing up without healthful dietary practices and described potential school-based interventions. For example,

"I think hitting the elementary school level and trying to motivate them because again those are going to be the people that grow up to have these bad eating habits or just be ignorant to some of the issues that can cause kidney failure".

\section{Food vouchers and other financial interventions}

Some participants endorsed financial interventions as a means to address low adherence to healthful diets among low income individuals. One participant remarked:

"I think it should be a program like that for different people with terminal illnesses or illnesses like kidney disease, because some people may not be able to afford 
to go get fresh vegetables and things, and if they had the vouchers to go get the fruits and vegetables or whatever they might need, they might help them in their diet".

\section{Discussion}

In this qualitative study, African Americans of low SES and who are at high risk for developing CKD perceived several barriers to CKD prevention through dietary change, including the expense and unavailability of healthy foods, family member preferences, convenience of unhealthy foods, and inability to break lifelong habits. They identified vouchers for healthy foods, home and/or family-based interventions, nutritional counseling and group gatherings for persons interested in making dietary changes as potentially acceptable approaches to preventing CKD.

As in a previous study of low-income, hypertensive African Americans' views of the DASH diet [38], our participants identified both socioeconomic and cultural barriers to following a DASH-like diet-and the two may be interrelated. A key barrier identified by our participants was limited accessibility and high cost of healthful foods. Consistent with participants' perceptions, the availability of affordable and nutritious food has been shown to be limited in many low income and/or minority communities, including those in Baltimore City $[39,40]$. Additionally, a recent meta-analysis of studies spanning 10 countries reported that healthier foods/diet patterns are more costly than less healthy foods [41]. Notably, these barriers to dietary modifications have been overcome in some low income communities who have implemented programs to increase availability of healthful and affordable foods [42,43]. However, improving access alone may not increase consumption of healthful foods if they are perceived to be culturally inappropriate [38] or less palatable [44].

Family member food preferences posed a significant challenge to our participants, and likely relate, in part, to cultural norms among African Americans [38]. There is a perception among some African Americans that healthful eating requires giving up part of their cultural heritage and conforming to the dominant culture [45]. The idea of giving up cultural norms is particularly at odds with the altruistic concept of family-based collectivism, which places the interests and needs of the family before those of the individual and is a core value for many racial minority groups [46]. While DASH diet recommendations have been presented in the context of soul food and other traditional diets in the African American community [47,48], effective adaptions of these recommendations have not fully penetrated highrisk populations. Thus, further efforts to make DASH diet recommendations which are culturally-tailored and acceptable to persons at risk for CKD and other consequences of hypertension, are warranted. Such approaches may aid in breaking the life-long habits our participants identified as significant barriers to dietary changes.

Potential facilitators of CKD prevention through dietary modifications detailed by our participants included individual, as well as home and community-based programs and interventions. Receipt of education from an individual who had personal experience with making dietary changes was viewed favorably by our participants. Similarly, focus group participants in an obesity prevention study among African American women preferred to learn about diet and physical activity from someone like them, as opposed to, for example, celebrities who were not viewed as credible given their access to resources unavailable to most [49].

The notable finding that none of our participants had prior knowledge of the DASH diet (despite over half reporting a diagnosis of hypertension) suggests substantial gaps in dissemination of evidence-based dietary approaches exist in this population, which is an opportunity for clinicians caring for African Americans at high risk for CKD. Home-based educational programs, as suggested by our participants, may be particularly effective in reaching disadvantaged populations who may face transportation, childcare and other barriers to clinicbased services [50]. For example, a home-based diabetes education trial among Hispanics led to significant reduction in hemoglobin A1c levels [51].

At age 40 years (the mean age of our study participants), African American men and women in the general U.S. population have a $16.8 \%$ and $18.9 \%$, respectively, lifetime risk of developing advanced CKD (estimated glomerular filtration rate $<30 \mathrm{ml} / \mathrm{min} / 1.73 \mathrm{~m}^{2}$ ) [52]. While participants in our study reported some knowledge of established causes and risk factors for CKD, and all had at least one biological risk factor for kidney disease (i.e. diabetes or hypertension), many did not consider themselves to be at high risk of developing CKD. For example, participants were generally aware that family history is an important determinant of CKD $[53,54]$ and all participants had at least one first degree family member with ESRD. Yet, consistent with a prior study from our group which was largely composed of African Americans at high-risk for CKD [23], few participants perceived their personal risk of CKD to be high. While this finding argues for increased education among African Americans at high risk for CKD, risk awareness alone may not suffice. Perceived susceptibility to CKD has been associated with poorer blood pressure management [23], suggesting that fatalistic attitudes about CKD might impede its prevention, perhaps particularly when patients face significant barriers to managing risk factors. 
Our study had limitations which should be considered. First, our focus groups included a relatively small number of participants and were conducted in an urban U.S. city. Additional concepts or themes might be generated by interviewing additional participants in the study area or participants in other settings. Furthermore, participants of research studies may be more activated around their health than non-participants, which could have influenced group discussions. Second, we used self-reported data to determine participants' clinical status, and did not recruit participants across strata of socio-demographic or clinical factors, therefore, certain groups may have been underrepresented. Third, we included participants with at least one indicator of low SES, however, individual differences across indicators (e.g. high educational attainment but low annual income) may have influenced participant responses. Fourth, we did not return the transcripts to participants to review, which may have impaired the accuracy of the inferences made from participant statements. Fifth, we did not assess the health literacy of our participants, and we did not specifically delineate between objective and perceived knowledge. By asking open-ended questions and asking participants to elaborate, we facilitated discussion of what was most likely perceived knowledge. To better differentiate, future work might include a validated survey of a similar population. Lastly, while the DASH diet has been associated with many favorable health outcomes, it has not been evaluated for its potential effect on CKD prevention in controlled studies. Thus, our study may serve to generate hypotheses for such future interventions.

To our knowledge, our study is among the first to report detailed views about the role of dietary interventions in CKD prevention among African Americans at high risk for CKD. We extended prior studies of barriers to healthful eating among African Americans by also elucidating potential facilitators of change in a population in need of targeted interventions As the body of literature on effective dietary strategies for reducing kidney injury continues to grow $[13,14]$ our findings may inform translation of these strategies to vulnerable populations.

\section{Conclusions}

African Americans of low SES and who are at high risk for developing CKD demonstrated limited perception of their risk status, but identified multiple barriers and potential facilitators of CKD prevention via dietary modifications which can inform tailored interventions and public health initiatives.

\section{Additional file}

Additional file 1: Focus group moderator's guide.
Competing interests

The authors declare that they have no competing interests.

\section{Authors' contributions}

AJ analyzed the focus group data and drafted the manuscript. LEB and CA contributed substantially to the design of the study, the interpretation of the data, and revised the manuscript. TC analyzed the focus group data contributed to the drafting of the manuscript. K.K. recruited participants for the study, organized the focus groups and contributed to the drafting of the manuscript. LLB contributed to the design of the study, moderated the focus group sessions and contributed to the drafting of the manuscript. YL contributed to the analysis of the quantitative data and to the drafting of the manuscript. DCC conceived of the study design, acquired funding for the study, analyzed and interpreted the data and critically revised the manuscript. All authors read and approved the final manuscript.

\section{Acknowledgements}

This work was supported by the National Kidney Foundation of Maryland and grant K23DK097184 from the National Institute of Diabetes and Digestive and Kidney Diseases, National Institutes of Health. The content is solely the responsibility of the authors and does not necessarily represent the official views of the National Institutes of Health. DCC was supported by the Harold Amos Medical Faculty Development Program of the Robert Wood Johnson Foundation and the Gilbert S. Omenn Anniversary Fellowship of the Institute of Medicine.

\section{Author details}

'Department of Medicine, Johns Hopkins University School of Medicine, Baltimore, Maryland, USA. ${ }^{2}$ Welch Center for Prevention, Epidemiology and Clinical Research, Johns Hopkins Medical Institutions, Baltimore, Maryland, USA. ${ }^{3}$ Department of Epidemiology, Johns Hopkins Bloomberg School of

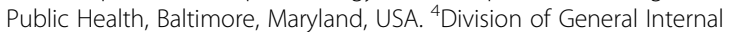
Medicine, Department of Medicine, Duke University, Durham, North Carolina, USA. ${ }^{5}$ Department of Family and Preventive Medicine, University of California San Diego, La Jolla, California, USA. Division of Nephrology, Department of Medicine, Johns Hopkins University School of Medicine, Baltimore, Maryland, USA. 'Division of Nephrology, Johns Hopkins University School of Medicine, Johns Hopkins Bayview Medical Center, 301 Mason F. Lord Drive, Suite 2500, Baltimore, MD 21224, USA.

Received: 14 July 2014 Accepted: 20 November 2014 Published: 6 December 2014

\section{References}

1. DeNavas-Walt CPPB, Smith JC: US Census Bureau, Current Population Reports, p 60-243, income, poverty, and health insurance coverage in the United States: 2011. Washington, DC: US Government Printing Office; 2012.

2. Crews DC, Pfaff T, Powe NR: Socioeconomic factors and racial disparities in kidney disease outcomes. Semin Nephrol 2013, 33(5):468-475.

3. Crews DC, Kuczmarski MF, Miller ER 3rd, Zonderman AB, Evans MK, Powe NR: Dietary Habits, Poverty, and Chronic Kidney Disease in an Urban Population. J Ren Nutr 2014, Sep 16. [Epub ahead of print].

4. Bomback AS, Derebail VK, Shoham DA, Anderson CA, Steffen LM, Rosamond WD, Kshirsagar AV: Sugar-sweetened soda consumption, hyperuricemia, and kidney disease. Kidney Int 2010, 77(7):609-616.

5. Chang A, Van Horn L, Jacobs DR Jr, Liu K, Muntner P, Newsome B, Shoham DA, Durazo-Arvizu R, Bibbins-Domingo K, Reis J, Kramer H: Lifestyle-related factors, obesity, and incident microalbuminuria: the CARDIA (Coronary Artery Risk Development in Young Adults) study. Am J Kidney Dis 2013, 62(2):267-275.

6. Gopinath B, Harris DC, Flood VM, Burlutsky G, Brand-Miller J, Mitchell P. Carbohydrate nutrition is associated with the 5-year incidence of chronic kidney disease. J Nutr 2011, 141(3):433-439.

7. Gutierrez OM, Muntner P, Rizk DV, McClellan WM, Warnock DG, Newby PK, Judd SE: Dietary Patterns and Risk of Death and Progression to ESRD in Individuals With CKD: A Cohort Study. Am J kidney Dis 2014, 64(2):204-213.

8. Lin J, Hu FB, Curhan GC: Associations of diet with albuminuria and kidney function decline. Clin J Am Soc Nephrol 2010, 5(5):836-843.

9. Scialla JJ, Appel LJ, Astor BC, Miller ER 3rd, Beddhu S, Woodward M, Parekh RS, Anderson CA, African American Study of Kidney D, Hypertension Study $\mathrm{G}$ : Net endogenous acid production is associated with a faster decline in GFR in African Americans. Kidney Int 2012, 82(1):106-112. 
10. Kanda E, Ai M, Kuriyama R, Yoshida M, Shiigai T: Dietary acid intake and kidney disease progression in the elderly. Am J Nephrol 2014, 39(2):145-152.

11. Lin J, Fung TT, Hu FB, Curhan GC: Association of dietary patterns with albuminuria and kidney function decline in older white women: a subgroup analysis from the Nurses' Health Study. Am J kidney Dis 2011, 57(2):245-254

12. Scialla JJ, Anderson CA: Dietary acid load: a novel nutritional target in chronic kidney disease? Adv Chronic Kidney Dis 2013, 20(2):141-149.

13. Goraya N, Simoni J, Jo C, Wesson DE: Dietary acid reduction with fruits and vegetables or bicarbonate attenuates kidney injury in patients with a moderately reduced glomerular filtration rate due to hypertensive nephropathy. Kidney Int 2012, 81(1):86-93.

14. Goraya N, Simoni J, Jo CH, Wesson DE: Treatment of metabolic acidosis in patients with stage 3 chronic kidney disease with fruits and vegetables or oral bicarbonate reduces urine angiotensinogen and preserves glomerular filtration rate. Kidney Int 2014, 86(5):1031-1038.

15. Seligman HK, Bindman AB, Vittinghoff E, Kanaya AM, Kushel MB: Food insecurity is associated with diabetes mellitus: results from the National Health Examination and Nutrition Examination Survey (NHANES) 1999-2002. J Gen Intern Med 2007, 22(7):1018-1023.

16. Block JP, Scribner RA, DeSalvo KB: Fast food, race/ethnicity, and income: a geographic analysis. Am J Prev Med 2004, 27(3):211-217.

17. Hiza HA, Casavale KO, Guenther PM, Davis CA: Diet quality of Americans differs by age, sex, race/ethnicity, income, and education level. J Acad Nutr Diet 2013, 113(2):297-306.

18. Mellen PB, Gao SK, Vitolins MZ, Goff DC Jr: Deteriorating dietary habits among adults with hypertension: DASH dietary accordance, NHANES 1988-1994 and 1999-2004. Arch Intern Med 2008, 168(3):308-314.

19. Svetkey LP, Simons-Morton D, Vollmer WM, Appel LJ, Conlin PR, Ryan DH, Ard J, Kennedy BM: Effects of dietary patterns on blood pressure: subgroup analysis of the Dietary Approaches to Stop Hypertension (DASH) randomized clinical trial. Arch Intern Med 1999, 159(3):285-293.

20. Airhihenbuwa CO, Kumanyika S, Agurs TD, Lowe A, Saunders D, Morssink CB: Cultural aspects of African American eating patterns. Ethn Health 1996, 1(3):245-260

21. Morland K, Wing S, Diez Roux A: The contextual effect of the local food environment on residents' diets: the atherosclerosis risk in communities study. Am J Public Health 2002, 92(11):1761-1767.

22. Tirodkar MA, Jain A: Food messages on African American television shows. Am J Public Health 2003, 93(3):439-441

23. Boulware LE, Carson KA, Troll MU, Powe NR, Cooper LA: Perceived susceptibility to chronic kidney disease among high-risk patients seen in primary care practices. J Gen Intern Med 2009, 24(10):1123-1129.

24. Waterman AD, Browne T, Waterman BM, Gladstone EH, Hostetter T: Attitudes and behaviors of African Americans regarding early detection of kidney disease. Am J Kidney Dis 2008, 51(4):554-562.

25. Jurkovitz C, Hylton TN, McClellan WM: Prevalence of family history of kidney disease and perception of risk for kidney disease: a population-based study. Am J Kidney Dis 2005, 46(1):11-17.

26. Crews DC, Charles RF, Evans MK, Zonderman AB, Powe NR: Poverty, race, and CKD in a racially and socioeconomically diverse urban population. Am J Kidney Dis 2010, 55(6):992-1000.

27. Crews DC, McClellan WM, Shoham DA, Gao L, Warnock DG, Judd S, Muntner P, Miller ER, Powe NR: Low income and albuminuria among REGARDS (Reasons for Geographic and Racial Differences in Stroke) study participants. Am J Kidney Dis 2012, 60(5):779-786.

28. Volkova N, McClellan W, Klein M, Flanders D, Kleinbaum D, Soucie JM, Presley R: Neighborhood poverty and racial differences in ESRD incidence. J Am Soc Nephrol 2008, 19(2):356-364.

29. McClellan WM, Warnock DG, Judd S, Muntner P, Patzer RE, Bradbury BD, McClure LA, Newsome BB, Howard G: Association of family history of ESRD, prevalent albuminuria, and reduced GFR with incident ESRD. Am J Kidney Dis 2012, 59(1):25-31.

30. Appel LJ, Moore TJ, Obarzanek E, Vollmer WM, Svetkey LP, Sacks FM, Bray GA, Vogt TM, Cutler JA, Windhauser MM, Lin PH, Karanja N: A clinical trial of the effects of dietary patterns on blood pressure. DASH Collaborative Research Group. New Eng J Med 1997, 336(16):1117-1124.

31. Forman JP, Stampfer MJ, Curhan GC: Diet and lifestyle risk factors associated with incident hypertension in women. JAMA 2009, 302(4):401-411.

32. Tobias DK, Hu FB, Chavarro J, Rosner B, Mozaffarian D, Zhang C: Healthful dietary patterns and type 2 diabetes mellitus risk among women with a history of gestational diabetes mellitus. Arch Internal Med 2012, 172(20):1566-1572.
33. Fung TT, Chiuve SE, McCullough ML, Rexrode KM, Logroscino G, Hu FB: Adherence to a DASH-style diet and risk of coronary heart disease and stroke in women. Arch Internal Med 2008, 168(7):713-720.

34. Tong A, Sainsbury P, Craig J: Consolidated criteria for reporting qualitative research (COREQ): a 32-item checklist for interviews and focus groups. Int J Qual Health Care 2007, 19(6):349-357.

35. Ameling JM, Auguste P, Ephraim PL, Lewis-Boyer L, DePasquale N, Greer RC, Crews DC, Powe NR, Rabb H, Boulware LE: Development of a decision aid to inform patients' and families' renal replacement therapy selection decisions. BMC Med Inform Decis Mak 2012, 12:140.

36. Watling CJ, Lingard L: Grounded theory in medical education research: AMEE Guide No. 70. Med Teach 2012, 34(10):850-861.

37. Birks M, Mills J: Grounded Theory: A practical guide. Los Angeles, CA: Sage Publication; 2011.

38. Bertoni AG, Foy CG, Hunter JC, Quandt SA, Vitolins MZ, Whitt-Glover MC A multilevel assessment of barriers to adoption of Dietary Approaches to Stop Hypertension (DASH) among African Americans of low socioeconomic status. J Health Care Poor Underserved 2011, 22(4):1205-1220.

39. Franco M, Diez Roux AV, Glass TA, Caballero B, Brancati FL: Neighborhood characteristics and availability of healthy foods in Baltimore. Am J Prev Med 2008, 35(6):561-567.

40. Casagrande SS, Franco M, Gittelsohn J, Zonderman AB, Evans MK, Fanelli Kuczmarski M, Gary-Webb TL: Healthy food availability and the association with BMI in Baltimore. Maryland Public Health Nutr 2011, 14(6):1001-1007.

41. Rao M, Afshin A, Singh G, Mozaffarian D: Do healthier foods and diet patterns cost more than less healthy options? A systematic review and meta-analysis. BMJ Open 2013, 3(12):e004277.

42. Abusabha R, Namjoshi D, Klein A: Increasing access and affordability of produce improves perceived consumption of vegetables in low-income seniors. J Am Diet Assoc 2011, 111(10):1549-1555.

43. Martin KS, Havens E, Boyle KE, Matthews G, Schilling EA, Harel O, Ferris AM: If you stock it, will they buy it? Healthy food availability and customer purchasing behaviour within corner stores in Hartford, CT. USA Public Health Nutr 2012, 15(10):1973-1978.

44. Offer A, Pechey R, Ulijaszek S: Obesity under affluence varies by welfare regimes: the effect of fast food, insecurity, and inequality. Econ Hum Biol 2010, 8(3):297-308

45. James DC: Factors influencing food choices, dietary intake, and nutrition-related attitudes among African Americans: application of a culturally sensitive model. Ethn Health 2004, 9(4):349-367.

46. Hays WC, Mindel CH: Extended kinship relations in Black and White families. J Marriage Fam 1973, 35(1):51-57.

47. Goodman J, Blake J: Nutrition education: a computer-based education program. J Health Care Poor Underserved 2005, 16(4 Suppl A):118-127.

48. Rankins J, Wortham J, Brown LL: Modifying soul food for the Dietary Approaches to Stop Hypertension diet (DASH) plan: implications for metabolic syndrome (DASH of Soul). Ethn Dis 2007, 17(3 Suppl 4):S4. -7-12.

49. Dietz W: Focus group data pertinent to the prevention of obesity in African Americans. Am J Med Scie 2001, 322(5):286-289.

50. Martin MY: Community health advisors effectively promote cancer screening. Ethn Dis 2005, 15(2 Suppl 2):S14-S16.

51. Duggan C, Carosso E, Mariscal N, Islas I, Ibarra G, Holte S, Copeland W, Linde S, Thompson B: Diabetes prevention in Hispanics: report from a randomized controlled trial. Prev Chronic Dis 2014, 11:E28.

52. Grams ME, Chow EK, Segev DL, Coresh J: Lifetime incidence of CKD stages 3-5 in the United States. Am J Kidney Dis 2013, 62(2):245-252

53. McClellan W, Speckman R, McClure L, Howard V, Campbell RC, Cushman M, Audhya P, Howard G, Warnock DG: Prevalence and characteristics of a family history of end-stage renal disease among adults in the United States population: Reasons for Geographic and Racial Differences in Stroke (REGARDS) renal cohort study. J Am Soc Nephrol 2007, 18(4):1344-1352.

54. McClellan WM, Satko SG, Gladstone E, Krisher JO, Narva AS, Freedman BI: Individuals with a family history of ESRD are a high-risk population for CKD: implications for targeted surveillance and intervention activities. Am J Kidney Dis 2009, 53(3 Suppl 3):S100-S106.

\section{doi:10.1186/1471-2369-15-194}

Cite this article as: Johnson et al:: Perceived barriers and facilitators of using dietary modification for CKD prevention among African Americans of low socioeconomic status: a qualitative study. BMC Nephrology 2014 15:194. 